\title{
Mobile-bearing versus fixed-bearing total knee arthroplasty: a meta-analysis of randomized controlled trials.
}

\author{
Ashraf T. Hantouly ${ }^{1} \cdot$ Abdulaziz F. Ahmed $^{1}$ (1) - Osama Alzobi ${ }^{1} \cdot$ Ammar Toubasi $^{1} \cdot$ Motasem Salameh $^{1}$. \\ Aissam Elmhiregh ${ }^{1}$. Shamsi Hameed ${ }^{1}$. Ghalib O. Ahmed ${ }^{1}$. Abtin Alvand ${ }^{2}$. Mohammed Al Ateeq Al Dosari ${ }^{1}$
}

Received: 24 January 2021 / Accepted: 9 April 2021 / Published online: 22 May 2021

(c) The Author(s) 2021

\begin{abstract}
Objective The purpose of this study was to perform a meta-analysis comparing mobile-bearing with fixed-bearing total knee arthroplasty (TKA) in terms of all-cause revision rates, aspetic loosening, knee functional scores, range of motion and radiographic lucent lines and osteolysis.

Methods PubMed, Cochrane Library, Google Scholar and Web of Science were searched up to January 2020. Randomized controlled trials that compared primary mobile-bearing with fixed-bearing TKA, reporting at least one of the outcomes of interest, at a minimum follow-up of 12 months were included. All outcomes of interest were pooled at short-term ( $<5$ years), mid-term (5 to 9 years) and long-term ( $>=10$ years) follow-up intervals.

Results A total of 70 eligible articles were included in the qualitative and statistical analyses. There was no difference between mobile-bearing or fixed-bearing TKA at short-term, mid-term and long-term follow-ups in all outcome measures including all-cause revision rate, aseptic loosening, oxford knee score, knee society score, Hospital for Special Surgery score, maximum knee flexion, radiographic lucent lines and radiographic osteolysis.

Conclusion The current level of evidence demonstrated that both mobile-bearing and fixed-bearing designs achieved excellent outcomes, yet it does not prove the theoretical advantages of the mobile-bearing insert over its fixed-bearing counterpart. The use of either design could therefore be supported based on the outcomes assessed in this study.

Level of Evidence: Level II, Therapeutic
\end{abstract}

Keywords Mobile $\cdot$ Fixed $\cdot$ Bearing $\cdot$ Total knee $\cdot$ Arthroplasty $\cdot$ Meta-analysis $\cdot$ Systematic review

\section{Introduction}

The design of the polyethylene insert has been debated numerously in the literature [22]. Fixed-bearing designs, which provide rigid fixation of the polyethylene insert within the tibial implant, have demonstrated satisfactory outcomes and long-term survival rates [1, 38, 45, 64]. However, implant loosening in fixed-bearing designs was theoretically attributed to higher contact stresses and polyethylene wear rates [20,75], which motivated the pursuit of improved TKA designs. Mobile-bearing polyethylene designs were

Abdulaziz F. Ahmed

afahmed@alumni.harvard.edu

1 Department of Orthopaedic Surgery, Surgical Specialty Center, Hamad Medical Corporation, Doha, Qatar

2 Nuffield Department of Orthopaedics, Rheumatology \& Musculoskeletal Sciences, University of Oxford, Oxford, UK developed to mitigate the drawbacks of fixed-bearing TKA through improving the conformity, lowering contact stresses with the aim of mimicking the kinematics of the native knee [16]. However, these advantages are theoretical and yet to be fully proven in vivo. Furthermore, mobile-bearing TKA can introduce unique complications such as bearing dislocation [5].

Earlier meta-analyses have reported superior results with the mobile-bearing TKA $[13,85]$. Subsequent meta-analysis with mid-term follow-up had refuted such findings without any significant difference between mobile-bearing and fixedbearing TKA [55, 81]. However, in June 2020 two recent meta-analyses with a limited number of studies presented further contradicting results, with one meta-analysis supporting long-term clinical outcomes in favor of mobile bearing, whereas the other meta-analysis refuted such findings $[15,84]$. Therefore, controversy continues to exist regarding the superiority of mobile-bearing over fixed-bearing designs. 
This study aimed to provide an updated meta-analysis comparing mobile-bearing versus fixed-bearing TKA using a multi-modal method of outcomes to include overall revision rates, aseptic loosening, clinical as well as radiological outcomes. Our hypothesis was that no significant differences exist in all outcomes between the mobile-bearing and the fixed-bearing designs.

\section{Materials and methods}

This meta-analysis was conducted with adherence to the Preferred Reporting Items for Systematic Reviews and Meta-Analyses (PRISMA) [54]. The focus was randomized controlled trials that compared mobile-bearing with fixedbearing TKA. The primary outcome was the all-cause revision rate. The secondary outcomes were aseptic loosening rates, knee functional scores, maximum knee flexion, radiographic lucent lines and osteolysis.

\section{Eligibility criteria}

The inclusion criteria were randomized controlled trials that compared primary mobile-bearing with fixed-bearing TKA, reporting at least one of the outcomes of interest, a minimum follow-up of 12 months. Exclusion criteria were inaccessible full-text, abstracts and studies reporting outcomes of interest but with unextractable data for meta-analytic comparisons. Articles published in English were only sought. Studies that reported the same sample population were not excluded if the follow-up intervals were different. The exclusion criteria were non-randomized clinical trials and studies with a population reported in a previous study with an overlapping follow-up interval.

\section{Information sources and search strategy}

PubMed, Cochrane Library, Google Scholar and Web of Science were searched till January 2020.

The search strategy involved the use of the following keywords that involved synonyms of "total knee arthroplasty" AND "mobile bearing" AND "fixed bearing" AND "randomized controlled trials."

Studies were screened by titles and abstracts. A full-text review was performed if a study matched the eligibility criteria. Furthermore, the references of each eligible article were manually searched to ensure eligible studies were not missed. The search strategy was performed by three authors independently. Any disagreement between the three authors in the search strategy was resolved by the senior author.

\section{Data collection process and data items}

The data items that were collected included: the first author's surname, study year, study location, age, sex, number of patients, type of prosthetic bearing used (mobile-bearing or fixed-bearing), the specific type of mobile-bearing prosthesis (rotating platform, rotating platform and gliding, and meniscal bearing), patella resurfacing, follow-up timepoints, all-cause revision rates, Oxford Knee Scores (OKS), Knee Society Scores (KSS), the Hospital for Special Surgery (HSS) knee scores, reported maximum knee flexion, radiographic radiolucent lines, radiographic osteolysis and rates of aseptic loosening. The OKS was transformed into the 0-48 scale to facilitate data synthesis. The Western Ontario and McMaster Universities Arthritis Index was not collected as it was reported variably among studies with the $0-96$ Likert scores or the 0-100 visual analog scales. Data collection forms were used independently by three authors, with any arising disagreement in the collected data being resolved by the senior author.

\section{Risk of bias in individual studies}

The qualitative analysis was performed with the revised Cochrane risk-of-bias tool for randomized trials (RoB 2) [74]. The tool contains five domains that assesses the randomization, adherence to intended treatments, missing outcomes, measurement bias and reporting bias. Each study was assessed with the RoB 2 by three authors independently, and the final rating of each study was reviewed by the three authors and the senior author to arrive at a consensus.

\section{Statistical analysis}

Analysis was performed with the use of Stata/IC (StataCorp. 2019. Stata Statistical Software: Release 16. College Station, TX: StataCorp LLC.). The outcomes were estimated with the use of $95 \%$ confidence interval (CI). The risk ratio (RR) was utilized for dichotomous outcomes such as the revision rates and the aseptic loosening rates. The mean difference (MD) was used for expressing continuous outcomes such as the OKS, the KSS and the HSS knee score. The Hedge's G mean difference was used for maximum knee flexion due to potential variability in the range of motion measurements. The outcome measures of interest were pooled at three different follow-up intervals at short term $(<5$ years $)$, mid-term ( 5 to 9 years) and long term ( $>=10$ years). The meta-analytic models were based on random effects (RE) with the use of the DerSimonian-Laird method as a heterogeneity variance estimator [17]. The formulas developed by Hozo et al.[31] 
were used in studies that reported medians instead of means and ranges instead of standard deviations (SD).

\section{Results}

\section{Study selection}

The search strategy resulted in 581 (569 articles from database search and 12 articles from manual references search) articles, of which 409 articles were excluded due to duplications. Subsequently, a total of 172 articles were screened by titles and abstracts, of which 67 articles were excluded. This resulted in a total of 105 articles that were eligible for full-text reviews, of which 35 articles were excluded. Thus, a total of 70 articles were included in the qualitative and statistical analyses. The PRISMA flowchart is displayed in Fig. 1.

\section{Study characteristics}

Among the 70 included studies, 4968 patients underwent mobile-bearing TKA and 5034 patients underwent fixedbearing TKA. The most utilized TKA implant was PFC Sigma® (DePuy) in $34.3 \%$ of all studies. A posterior-stabilized (PS) implant was routinely used in $60 \%$ of studies, whereas a cruciate-retaining (CR) design was routinely used in $25.7 \%$. The rest of the studies used either CR or PS designs $(4.3 \%)$ depending on the total knee system utilized, and $10 \%$ of studies did not specify whether the posterior cruciate ligament was sacrificed. The mobile-bearing designs used were a rotating platform in $81.4 \%$, rotating and anterior-posterior gliding in $11.4 \%$ and meniscal bearing in $2.86 \%$. Patella resurfacing was performed routinely in $48.57 \%$ of studies, unresurfaced in $22.86 \%$ and selectively resurfaced on a case-by-case basis in $17.14 \%$. Study characteristics are summarized in Table 1.

Fig. 1 Search strategy flowchart

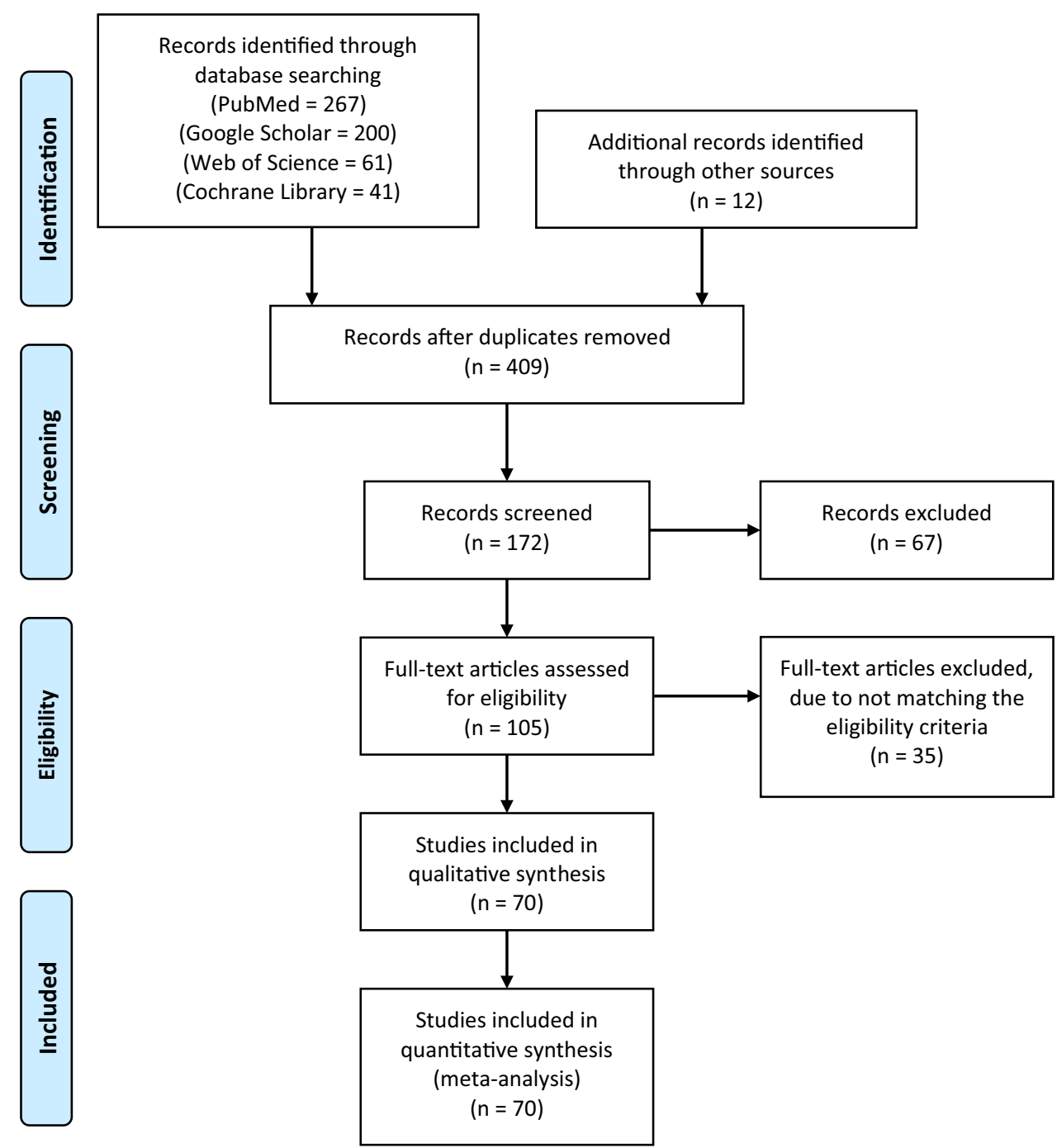




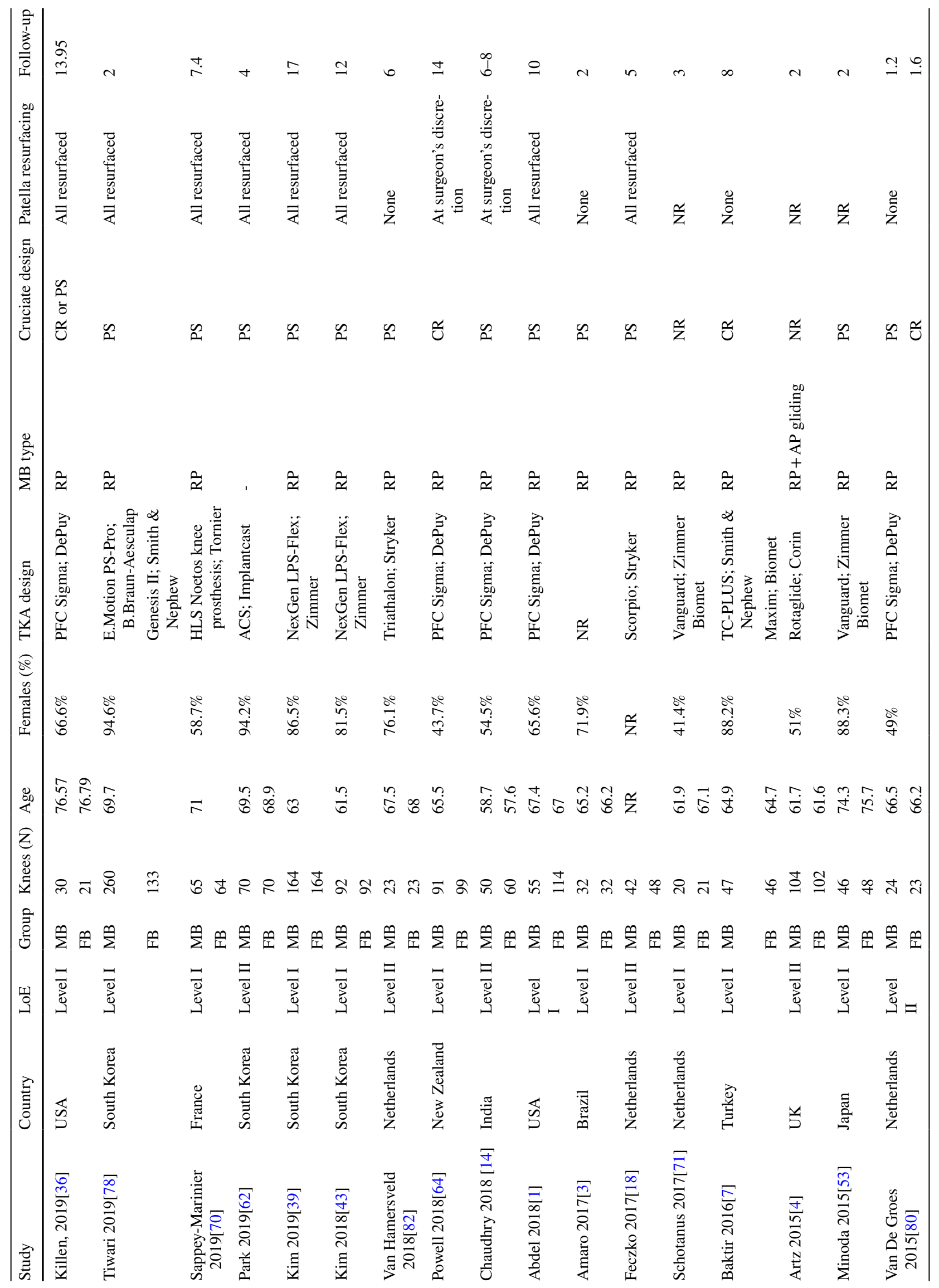




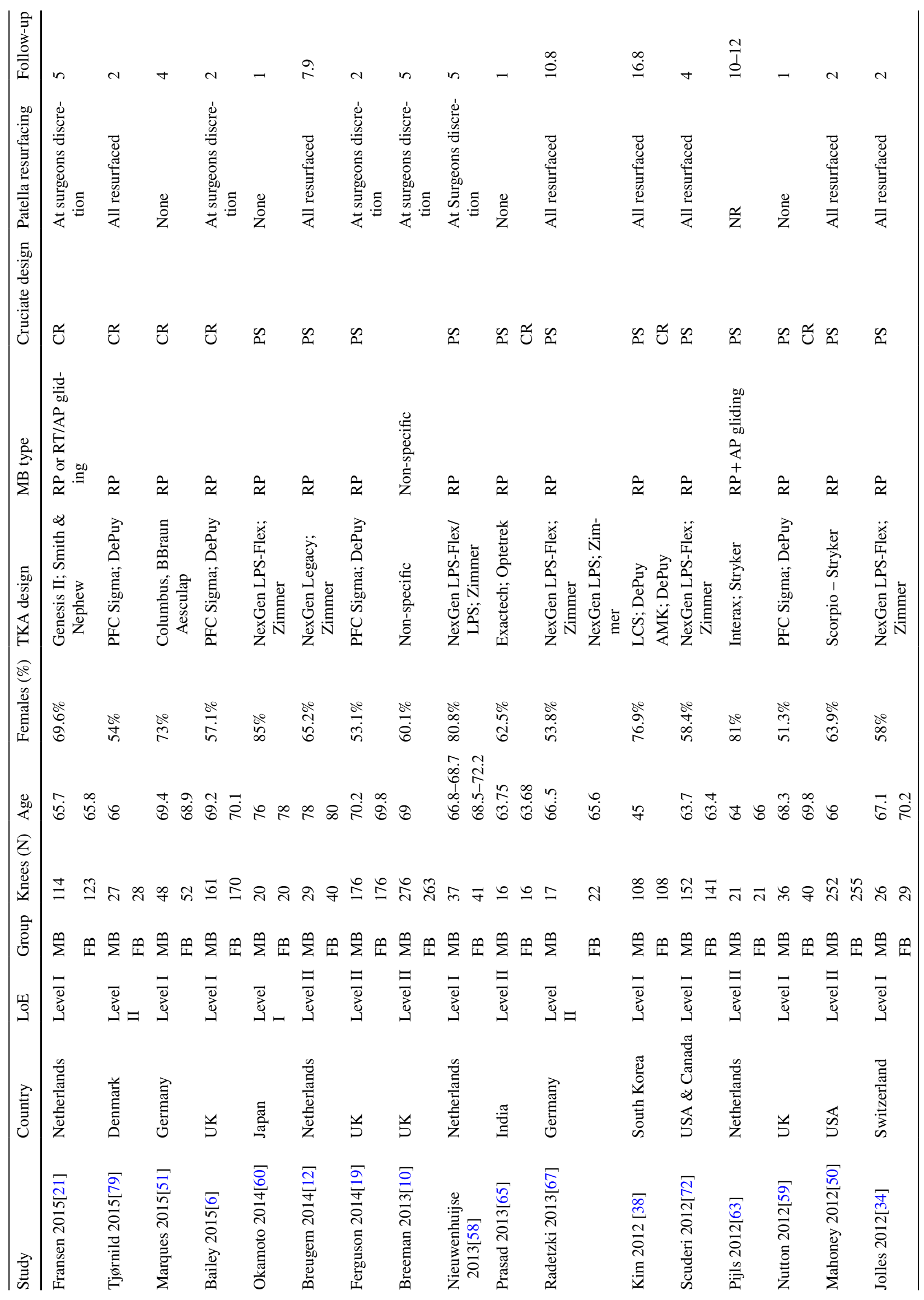




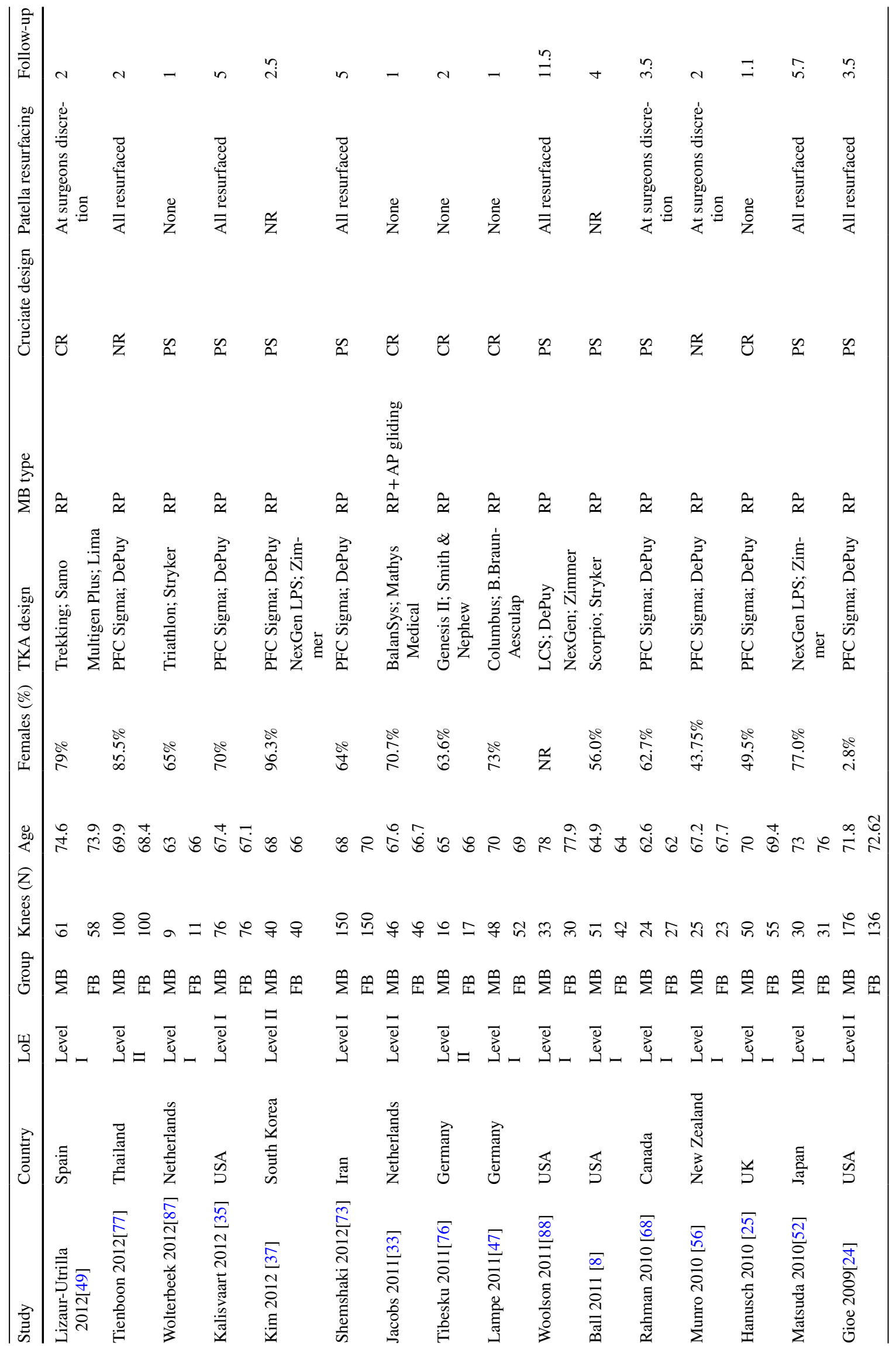




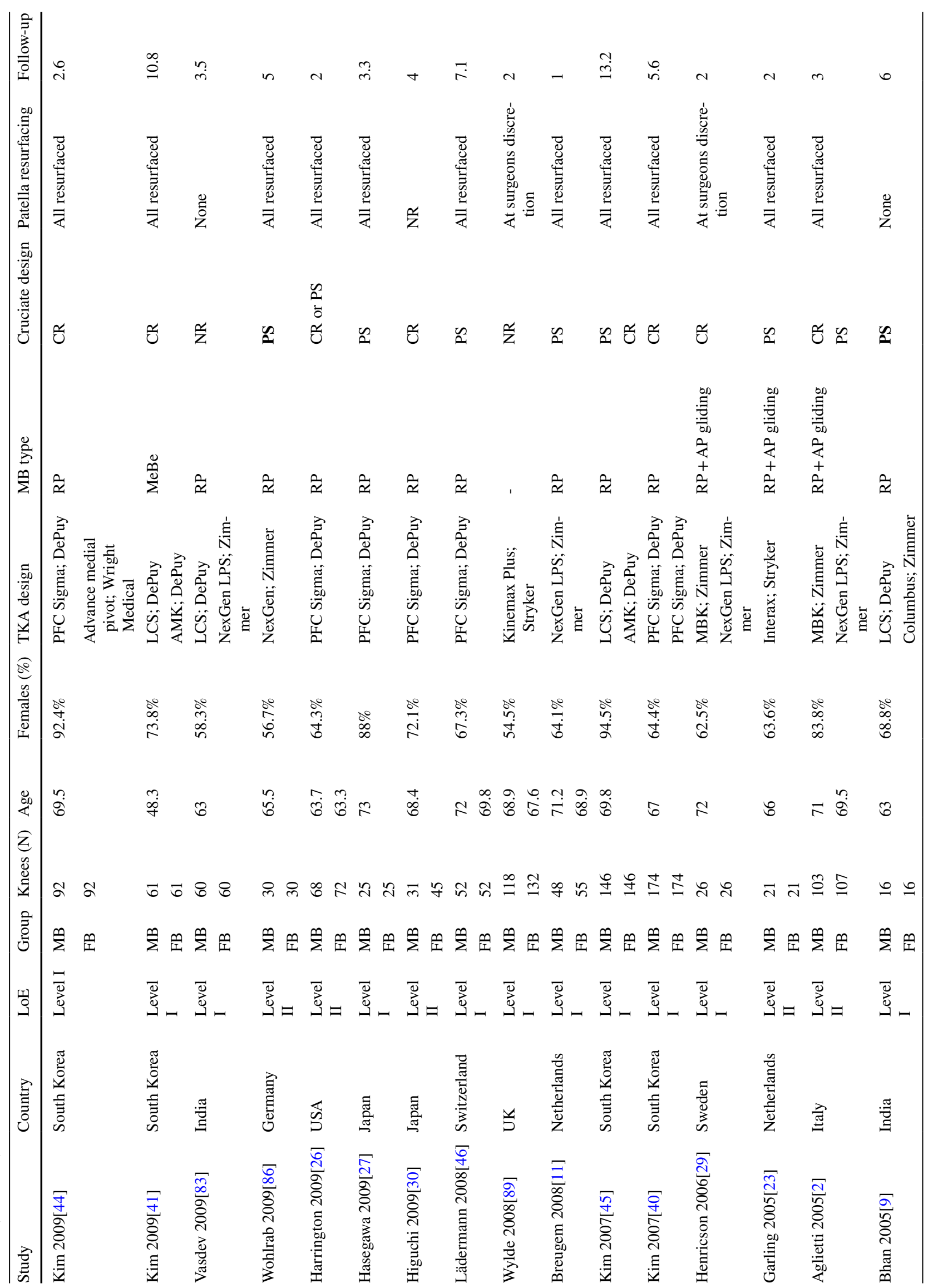




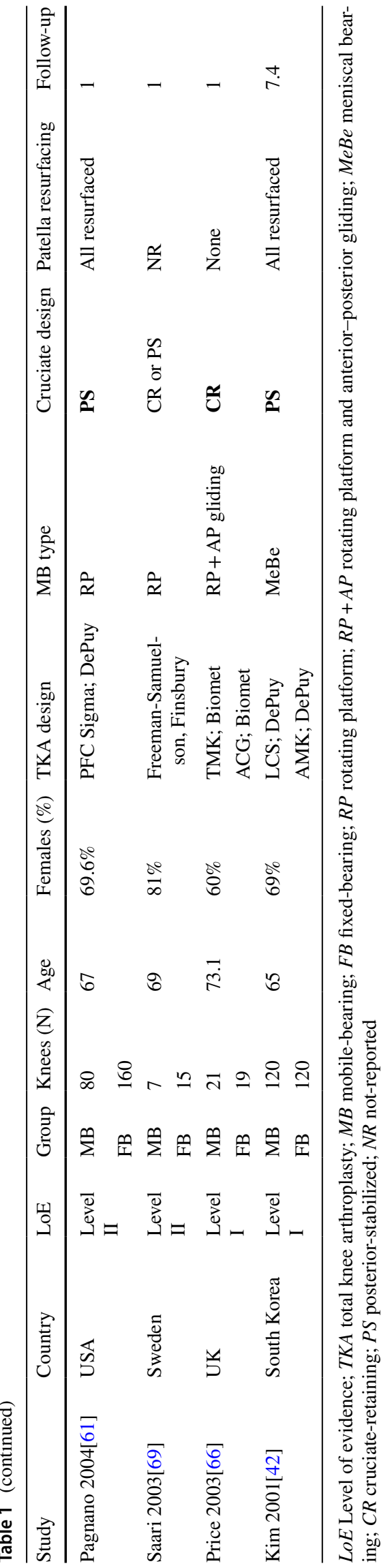

\section{Quality assessment}

Low risk of bias was found in 27 studies, some concern for bias in 28 studies and high risk of bias in the remaining 15 studies. Most studies had a low risk of bias for deviation from intended interventions, missing outcome data, measurement of outcomes and in the selection of reported results. In terms of randomization, $55.7 \%$ of included studies had a low risk of bias, $38.5 \%$ had some concern for bias, and $5.7 \%$ had a high risk for bias. A graphic summary of the qualitative assessment is displayed in Supplementary Fig. 1.

\section{Revision Rates}

Revisions were reported in 58 studies, with $2.4 \%$ (96 out of 3978) revision rates in mobile-bearing TKA and 2.2\% (88 out of 3947) revision rate in fixed-bearing TKA. The allcause revision rates were not statistically significant when comparing mobile-bearing versus fixed-bearing TKA at short-term (RR 1.06; 95\% CI 0.7, 1.58; $\mathrm{P}=0.793 ; \mathrm{I}^{2}=0 \%$ ), mid-term (RR 1.39; 95\% CI 0.84, 2.29; $\mathrm{P}=0.197 ; \mathrm{I}^{2}=0 \%$ ) and long-term (RR 0.78; 95\% CI 0.45, 1.34; $\mathrm{P}=0.361$; $\left.\mathrm{I}^{2}=0 \%\right)$ follow-up intervals. Likewise, among 5 studies there was no significant difference in aseptic loosening at the three follow-up intervals (Fig. 2).

\section{Functional Scores}

Eleven and 3 studies reported the OKS at short and midterms, respectively. There was no significant difference between mobile-bearing and fixed-bearing TKA at both short term (MD 0.04; 95\% CI $-0.78,0.86 ; \mathrm{P}=0.926$; $\left.\mathrm{I}^{2}=0 \%\right)$ and mid-term (MD 0.94; (95\% CI -2.14, 4.02; $\mathrm{P}=0.551 ; \mathrm{I}^{2}=88.9 \%$ ) (Fig. 3).

The KSS knee and function sub-scores were reported in 24 studies at short-term, 14 studies at mid-term and 8 studies at long-term follow-up. There was no statistically significant difference between mobile-bearing and fixed-bearing TKA at short term (MD 0.36; 95\% CI -1.06, 1.78; $\mathrm{P}=0.619$; $\mathrm{I}^{2}=87.89 \%$ ) and mid-term (MD 1.00; 95\% CI -0.57, 2.59; $\mathrm{P}=0.209 ; \mathrm{I}^{2}=91.75 \%$ ) for the KSS knee sub-score. The long-term follow-up demonstrated statistically significant better KSS knee sub-score in favor of fixed-bearing TKA (MD - 1.21; 95\% CI -2.06, -0.37; P =0.005; $\mathrm{I}^{2}=0.39 \%$ ). Regarding the functional KSS sub-score, there were no statistically significant differences at short-term (MD 0.59; 95\% $\mathrm{CI}-2.13,3.31 ; \mathrm{P}=0.671 ; \mathrm{I}^{2}=90.98 \%$ ), mid-term (MD 0.65; $\left.95 \% \mathrm{CI}-3.01,4.32 ; \mathrm{P}=0.727 ; \mathrm{I}^{2}=96.2 \%\right)$ and long-term (MD $0.45 ; 95 \% \mathrm{CI}-0.37,1.26 ; \mathrm{P}=0.28 ; \mathrm{I}^{2}=0 \%$ ) follow-ups between mobile-bearing and fixed-bearing TKA. Figure 3 displays the KSS sub-score comparisons.

The HSS knee score was reported in 8 studies at short term, 3 studies at mid-term and 3 studies at long term. The 


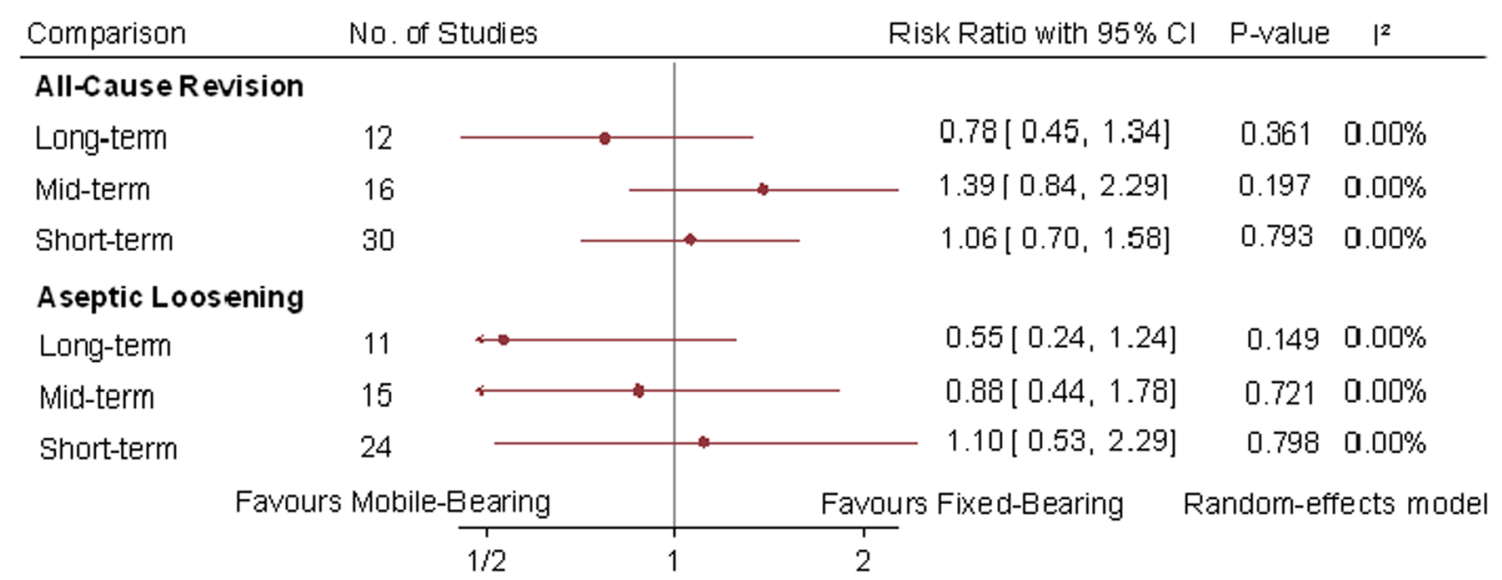

Fig. 2 Random-effect meta-analytic comparison for all-cause revision and aseptic loosening between mobile-bearing versus fixed-bearing total knee arthroplasty. CI: confidence interval

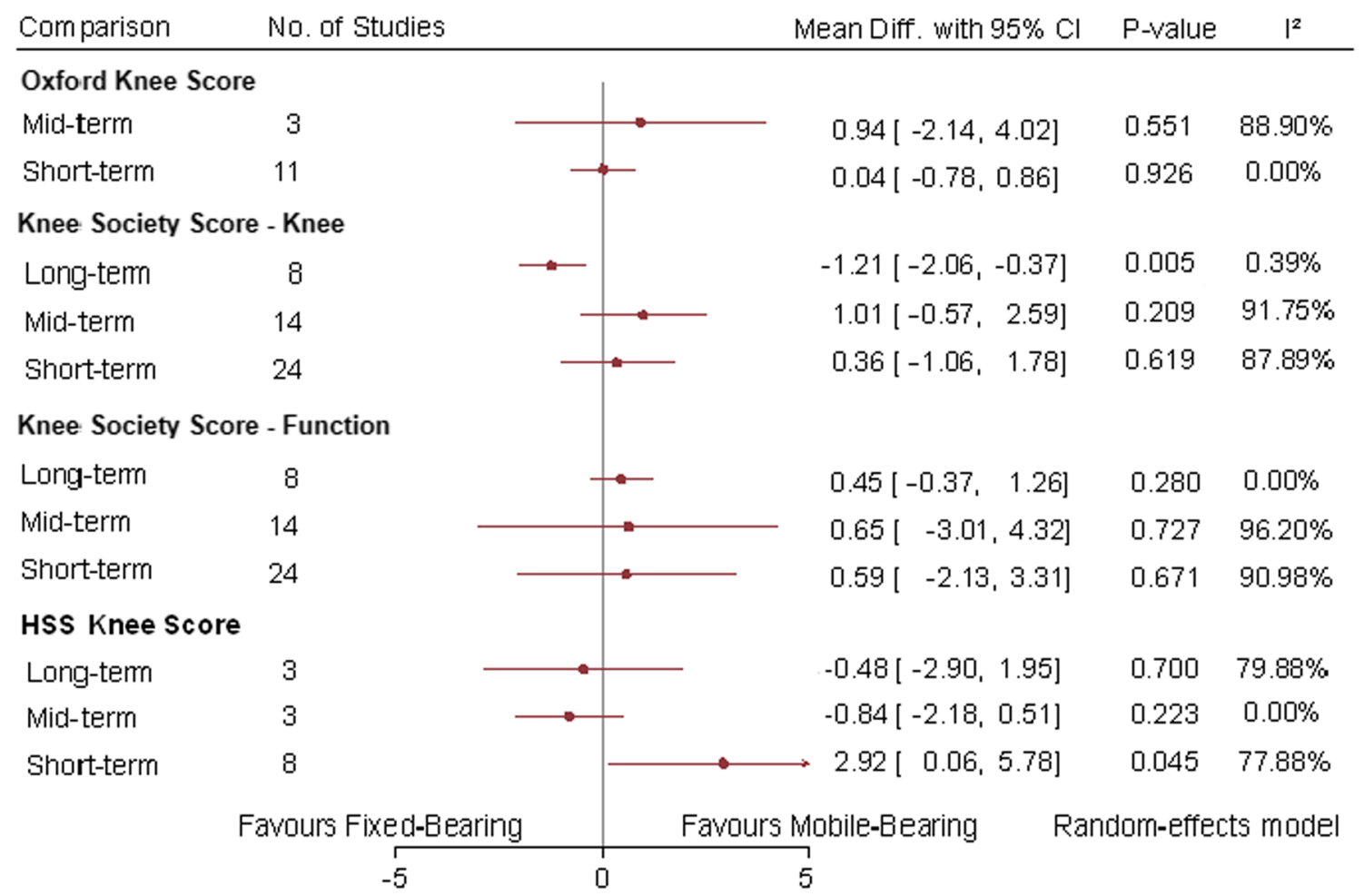

Fig. 3 Random-effect meta-analytic comparison for functional knee scores between mobile-bearing versus fixed-bearing total knee arthroplasty. CI: confidence interval

short-term follow-up comparison demonstrated slightly better HSS scores in favor of mobile-bearing TKA (MD $2.92 ; 95 \%$ CI $\left.0.06,5.78 ; \mathrm{P}=0.045 ; \mathrm{I}^{2}=77.88 \%\right)$. The midterm (MD $\left.-0.84 ; 95 \% \mathrm{CI}-2.18,0.51 ; \mathrm{P}=0.223 ; \mathrm{I}^{2}=0 \%\right)$ and long-term ( $\mathrm{MD}-0.48 ; 95 \% \mathrm{CI}-2.9,1.95 ; \mathrm{P}=0.7$; $\mathrm{I}^{2}=79.88 \%$ ) follow-up intervals did not demonstrate any statistically significant difference for the HSS knee scores (Fig. 3).
The range of motion was reported in 27 studies at short term, 12 studies at mid-term and 6 studies at long term. No differences were significant between mobile-bearing and fixed-bearing TKA at any of the three follow-up intervals (Fig. 4). 


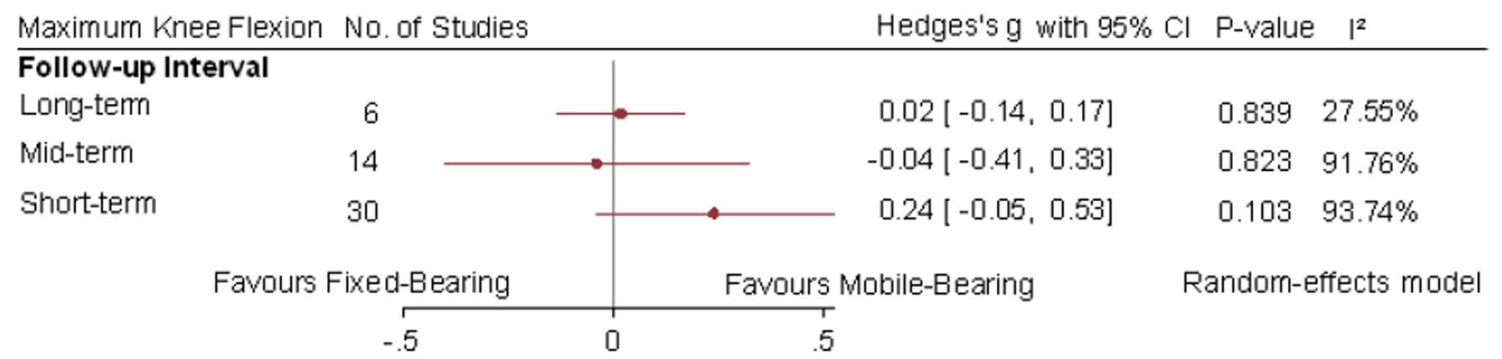

Fig. 4 Random-effect meta-analytic comparison for maximum knee flexion between mobile-bearing versus fixed-bearing total knee arthroplasty. CI: confidence interval

\section{Radiographic outcomes}

Radiolucent lines were pooled in 14 studies at shortterm, 11 studies at mid-term and 9 studies at long-term follow-up intervals. There was no statistically significant difference at short-term (RR 1.17; 95\% CI 0.99, 1.4; $\left.\mathrm{P}=0.072 ; \mathrm{I}^{2}=0 \%\right)$, mid-term (RR 0.95; 95\% CI 0.76, 1.17; $\mathrm{P}=0.615 ; \mathrm{I}^{2}=0 \%$ ) or long-term (RR $0.9 ; 95 \%$ CI 0.62 , $1.31 ; \mathrm{P}=0.588 ; \mathrm{I}^{2}=27.87 \%$ ) intervals between mobilebearing and fixed-bearing TKA (Fig. 5).

Osteolysis was pooled in 14 studies at short-term, 10 studies at mid-term and 8 studies at long-term follow-up intervals. Meta-analytic comparison of mobile-bearing TKA with fixed-bearing TKA failed to demonstrate any statistically significant difference at short-term (RR 0.76; 95\% CI 0.28, 2.08; P=0.592; $\left.\mathrm{I}^{2}=0 \%\right)$, mid-term (RR $0.768 ; 95 \%$ CI $\left.0.23,2.49 ; \mathrm{P}=0.647 ; \mathrm{I}^{2}=0 \%\right)$ and longterm intervals (RR $0.83 ; 95 \%$ CI $0.35,1.97 ; \mathrm{P}=0.675$; $\left.\mathrm{I}^{2}=0 \%\right)($ Fig. 5).

\section{Discussion}

This meta-analysis on randomized controlled trials demonstrated no significant difference between mobile-bearing and fixed-bearing TKA with regard to all outcome measures compared. The revision rates among studies throughout all follow-up intervals were $2.4 \%$ in mobile-bearing TKA and $2.2 \%$ in fixed-bearing TKA. Furthermore, this metaanalysis did not result in statistically significant differences in revision rates or aseptic loosening between both designs at short-term, mid-term and long-term follow-up intervals. The long-term follow-up interval ranged from 10 to 17 years postoperatively in 12 studies for revision rates and 11 studies for aseptic loosening. Likewise, previous meta-analyses and the vast majority of included randomized trials found similar survivorship when comparing mobile-bearing and fixedbearing TKA [55, 81]. In contrast, few non-randomized studies have found contradicting evidence. A registry-based prospective study by Namba et al. [57] on 47,339 knees found that mobile-bearing TKA had a twofold increase in

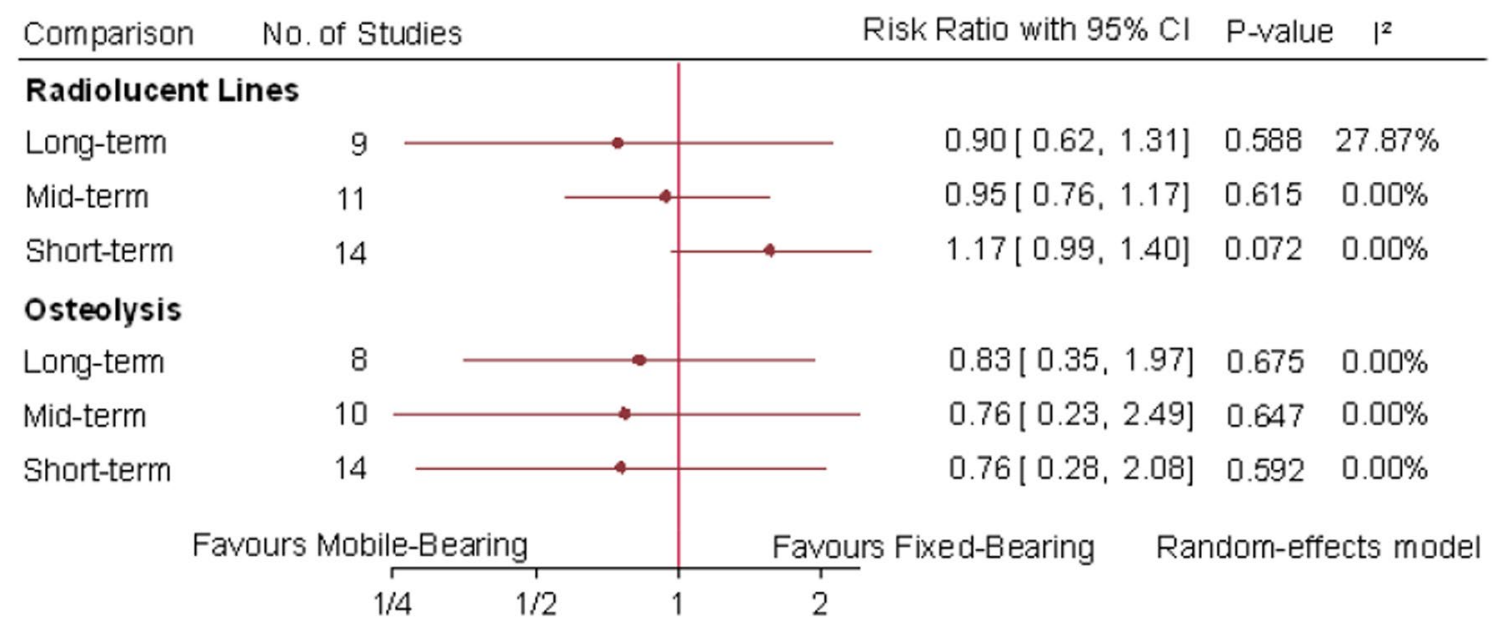

Fig. 5 Random-effects meta-analytic comparison for radiolucent lines and osteolysis between mobile-bearing versus fixed-bearing total knee arthroplasty. CI: confidence interval 
aseptic revision at 6.7 years when compared to fixed-bearing TKA following a multi-variate adjusted regression analysis $(\mathrm{P}<0.001)$. Likewise, Heesterbeek et al. [28] found in a recent multicenter retrospective study that fixed-bearing had superior survivorship at 12 years as opposed to mobilebearing designs. In a randomized trial by Fransen et al. [21], mobile-bearing TKA was found to have a 6-times higher risk for all-cause revision compared to fixed-bearing TKA at 5-year follow-up. This study had major limitations such as a $38 \%$ drop-out rate and lack of blinding of those who assessed outcomes.

Assessment of knee functional outcomes demonstrated no clinically significant differences between mobile-bearing and fixed-bearing TKAs. The OKS was only pooled at the short- and the mid-term follow-up intervals without any statistical significance. The KSS knee sub-score was not statistically significant at the short- and the mid-term follow-up intervals; however, at the long-term there was a statistically significant effect in favor of fixed-bearing TKA. It is paramount to acknowledge that this finding was not clinically significant as the minimal clinically important difference (MCID) of the KSS knee sub-score is between 5.3 and 5.9 points [48]. The KSS functional sub-score was statistically insignificant at short-, mid- and long-term follow-ups. The HSS knee score was in favor of mobile-bearing TKA at the short-term follow-up which was statistically significant, however, yet clinically irrelevant as the HSS MCID is 8.29 points [32]. The mid- and the long-term follow-up for the HSS knee score had no statistically significant difference between mobile-bearing and fixed-bearing TKA. Furthermore, there was no statistically significant difference between mobile-bearing and fixed-bearing TKA for the postoperative maximum knee flexion. Most prior meta-analyses and randomized trials have shown similar results without any statistical difference in clinical outcomes. Nonetheless, several studies have had better outcomes with mobilebearing TKA. At 6-10-year follow-up, the randomized trial Baktir et al. [7] resulted in significantly improved pain and KSS knee sub-scores in mobile-bearing TKA. However, the authors found no difference in the functional sub-score of the KSS. In a recent randomized trial by Powell et al. [64], mobile-bearing TKA had superior results with the OKS and the Knee Injury and Osteoarthritis Outcome Score sports and quality of life subscales. This difference was observed at 10-year follow-up which exceeded the MCID threshold. In contrast, a similarly well-designed trial by Abdel et al. [1] refuted such findings without any advantages provided by the mobile-bearing design over fixed-bearing TKA in terms of maximum knee flexion or function at 10-year follow-up.

In terms of radiological outcomes, no significant differences were detected between both mobile-bearing and fixedbearing TKA at the short-, mid- and long-term follow-up intervals for either radiolucent lines or osteolysis. In all randomized trials included except for the study by Bailey et al. [6], there was no statistical difference between mobilebearing and fixed-bearing designs in radiological outcomes. Bailey et al. [6] have reported that radiolucency was higher in the mobile-bearing designs around the tibial component; however, this was clinically insignificant. Furthermore, in a radiostereometric analysis (RSA) by Schotanus et al. [71] both mobile-bearing and fixed-bearing designs had similar implant migration detected by the maximum total point motion at 2 years.

The strengths of this study were the inclusion of the largest number of randomized trials thus far, and the analyzing outcomes measure at the short-, mid- and long-term followup intervals. To the best of our knowledge, this is the most comprehensive recent meta-analysis on the topic. The last systematic review was performed in 2017 by Fransen et al. [22]. In addition, the last two meta-analyses were performed in June 2020 on this topic by Chen et al. [15] and Wang et al. [84]; however, both meta-analyses combined had 16 randomized trials versus 70 randomized trials in our meta-analysis. Furthermore, both meta-analyses had conflicting results as one supported long-term outcomes of mobile-bearing TKA, yet the other found no difference between fixed-bearing and mobile-bearing designs. In contrast, our study found no differences between mobile- and fixed-bearing designs at anytime point; this is mainly due to pooling data from 70 RCTs, thereby demonstrating more valid results. Several limitations to this meta-analysis should be acknowledged. Although we included RCTs, several trials had high risk of bias as evident in our qualitative review. Another limitation was that outcome measures varied among included studies, which prevented measuring the long-term outcome using the OKS and pooling a higher number of patients in other outcome measures. Implant migration using RSA was not analyzed due to the variability in its reporting across RSAbased studies. Another important limitation was that different types of mobile-bearing TKA were used by different trials, in turn this could be a potential source of bias given the mobile-bearing type was not adjusted for.

\section{Conclusion}

This meta-analysis on 70 randomized controlled trials demonstrated no clinically significant differences between mobile-bearing and fixed-bearing TKA at short-, mid- and long-term follow-up for revision rates, aseptic loosening rates, knee functional scores, maximum knee flexion and radiographic lucent lines and osteolysis. The current level of evidence demonstrated that both mobile-bearing and fixedbearing designs achieved excellent outcomes, yet it does not prove the theoretical advantages of the mobile-bearing insert over its fixed-bearing counterpart. Given that the use 
of either design can be supported by this meta-analysis, we recommend that surgeons can use mobile- or fixed-bearing inserts in TKA at their own discretion.

Supplementary information The online version contains supplementary material available at (https://doi.org/10.1007/ s00590-021-02999-x).

Authors' contribution AH, OZ, AT performed the literature search and collected the data. MS, AE performed the quality assessment. AFA conceived the study and performed the statistical analysis. SH, GO, $\mathrm{AA}$ and MAA helped in preparing the manuscript and supervising the whole work.

Funding Open access funding provided by the Qatar National Library. None.

Availability of data and material Not applicable.

Code availability Not applicable.

\section{Declarations}

Conflicts of interest On behalf of all authors, the corresponding author states that there was no conflict of interest.

Consent to participate Not applicable.

Consent for publication Not applicable.

Ethical approval This article does not contain any studies with human participants performed by any of the authors.

Open Access This article is licensed under a Creative Commons Attribution 4.0 International License, which permits use, sharing, adaptation, distribution and reproduction in any medium or format, as long as you give appropriate credit to the original author(s) and the source, provide a link to the Creative Commons licence, and indicate if changes were made. The images or other third party material in this article are included in the article's Creative Commons licence, unless indicated otherwise in a credit line to the material. If material is not included in the article's Creative Commons licence and your intended use is not permitted by statutory regulation or exceeds the permitted use, you will need to obtain permission directly from the copyright holder. To view a copy of this licence, visit http://creativecommons.org/licenses/by/4.0/.

\section{References}

1. Abdel MP, Tibbo ME, Stuart MJ, Trousdale RT, Hanssen AD, Pagnano MW (2018) A randomized controlled trial of fixed- versus mobile-bearing total knee arthroplasty: a follow-up at a mean of ten years. Bone Joint J 100-B:925-929

2. Aglietti P, Baldini A, Buzzi R, Lup D, De Luca L (2005) Comparison of mobile-bearing and fixed-bearing total knee arthroplasty: a prospective randomized study. $\mathbf{J}$ Arthroplasty

3. Amaro JT, Arliani GG, Astur DC, Debieux P, Kaleka CC, Cohen M (2017) No difference between fixed- and mobile-bearing total knee arthroplasty in activities of daily living and pain: a randomized clinical trial. Knee Surg Sports Traumatol Arthrosc 25:1692-1696

4. Artz NJ, Hassaballa MA, Robinson JR, Newman JH, Porteous AJ, Murray JR (2015) Patient Reported Kneeling Ability in Fixed and Mobile Bearing Knee Arthroplasty. J Arthroplasty 30:2159-2163

5. Bae JH, Kim JG, Lee SY, Lim HC, In Y, group MS, (2020) Epidemiology of bearing dislocations after mobile-bearing unicompartmental knee arthroplasty: multicenter analysis of 67 bearing dislocations. J Arthroplasty 35:265-271

6. Bailey O, Ferguson K, Crawfurd E, James P, May PA, Brown S et al (2015) No clinical difference between fixed- and mobilebearing cruciate-retaining total knee arthroplasty: a prospective randomized study. Knee Surg Sports Traumatol Arthrosc 23:1653-1659

7. Baktir A, Karaaslan F, Yurdakul E, Karaoglu S (2016) Mobileversus fixed-bearing total knee arthroplasty: a prospective randomized controlled trial featuring 6-10-year follow-up. Acta Orthop Traumatol Turc 50:1-9

8. Ball ST, Sanchez HB, Mahoney OM, Schmalzried TP (2011) Fixed versus rotating platform total knee arthroplasty: a prospective, randomized, single-blind study. J Arthroplasty 26:531-536

9. Bhan S, Malhotra R, Kiran EK, Shukla S, Bijjawara M (2005) A comparison of fixed-bearing and mobile-bearing total knee arthroplasty at a minimum follow-up of 4.5 years. J Bone Joint Surg Am 87:2290-2296

10. Breeman S, Campbell MK, Dakin H, Fiddian N, Fitzpatrick R, Grant A et al (2013) Five-year results of a randomised controlled trial comparing mobile and fixed bearings in total knee replacement. Bone Joint J 95-b:486-492

11. Breugem SJ, Sierevelt IN, Schafroth MU, Blankevoort L, Schaap GR, van Dijk CN (2008) Less anterior knee pain with a mobilebearing prosthesis compared with a fixed-bearing prosthesis. Clin Orthop Relat Res 466:1959-1965

12. Breugem SJ, van Ooij B, Haverkamp D, Sierevelt IN, van Dijk CN (2014) No difference in anterior knee pain between a fixed and a mobile posterior stabilized total knee arthroplasty after 7.9 years. Knee Surg Sports Traumatol Arthrosc 22:509-516

13. Carothers JT, Kim RH, Dennis DA, Southworth C (2011) Mobilebearing total knee arthroplasty: a meta-analysis. J Arthroplasty 26:537-542

14. Chaudhry A, Goyal VK (2018) Fixed-bearing versus high-flexion RP total knee arthroplasty (TKA): midterm results of a randomized controlled trial. J Orthop Traumatol 19:2

15. Chen P, Huang L, Zhang D, Zhang X, Ma Y, Wang Q (2020) Mobile bearing versus fixed bearing for total knee arthroplasty: meta-analysis of randomized controlled trials at minimum 10-year follow-up. J Knee Surg. https://doi.org/10.1055/s-0040-1713356

16. D'Lima DD, Trice M, Urquhart AG, Colwell CW Jr (2001) Tibiofemoral conformity and kinematics of rotating-bearing knee prostheses. Clin Orthop Relat Res 386:235-242

17. DerSimonian R, Laird N (1986) Meta-analysis in clinical trials. Control Clin Trials 7:177-188

18. Feczko PZ, Jutten LM, van Steyn MJ, Deckers P, Emans PJ, Arts JJ (2017) Comparison of fixed and mobile-bearing total knee arthroplasty in terms of patellofemoral pain and function: a prospective, randomised, controlled trial. BMC Musculoskelet Disord 18:279

19. Ferguson KB, Bailey O, Anthony I, James PJ, Stother IG, M J G B, (2014) A prospective randomised study comparing rotating platform and fixed bearing total knee arthroplasty in a cruciate substituting design-outcomes at two year follow-up. Knee 21:151-155

20. Fisher J, McEwen H, Tipper J, Jennings L, Farrar R, Stone M et al (2006) Wear-simulation analysis of rotating-platform mobilebearing knees. Orthopedics 29:S36-41

21. Fransen BL, Hoozemans MJ, Keijser LC, van Lent ME, Verheyen CC, Burger BJ (2015) Does insert type affect clinical and 
functional outcome in total knee arthroplasty? a randomised controlled clinical trial with 5-year follow-up. J Arthroplasty 30:1931-1937

22. Fransen BL, van Duijvenbode DC, Hoozemans MJM, Burger BJ (2017) No differences between fixed- and mobile-bearing total knee arthroplasty. Knee Surg Sports Traumatol Arthrosc 25:1757-1777

23. Garling EH, Valstar ER, Nelissen RG (2005) Comparison of micromotion in mobile bearing and posterior stabilized total knee prostheses: a randomized RSA study of 40 knees followed for 2 years. Acta Orthop 76:353-361

24. Gioe TJ, Glynn J, Sembrano J, Suthers K, Santos ER, Singh J (2009) Mobile and fixed-bearing (all-polyethylene tibial component) total knee arthroplasty designs. a prospective randomized trial. J Bone Joint Surg Am 91:2104-2112

25. Hanusch B, Lou TN, Warriner G, Hui A, Gregg P (2010) Functional outcome of PFC Sigma fixed and rotating-platform total knee arthroplasty. A prospective randomised controlled trial. Int Orthop 34:349-354

26. Harrington MA, Hopkinson WJ, Hsu P, Manion L (2009) Fixed- vs mobile-bearing total knee arthroplasty: does it make a difference?-a prospective randomized study. J Arthroplasty 24:24-27

27. Hasegawa M, Sudo A, Uchida A (2009) Staged bilateral mobilebearing and fixed-bearing total knee arthroplasty in the same patients: a prospective comparison of a posterior-stabilized prosthesis. Knee Surg Sports Traumatol Arthrosc 17:237-243

28. Heesterbeek PJC, van Houten AH, Klenk JS, Eijer H, Christen B, Wymenga AB et al (2018) Superior long-term survival for fixed bearing compared with mobile bearing in ligamentbalanced total knee arthroplasty. Knee Surg Sports Traumatol Arthrosc 26:1524-1531

29. Henricson A, Dalen T, Nilsson KG (2006) Mobile bearings do not improve fixation in cemented total knee arthroplasty. Clin Orthop Relat Res 448:114-121

30. Higuchi H, Hatayama K, Shimizu M, Kobayashi A, Kobayashi T, Takagishi K (2009) Relationship between joint gap difference and range of motion in total knee arthroplasty: a prospective randomised study between different platforms. Int Orthop 33:997-1000

31. Hozo SP, Djulbegovic B, Hozo I (2005) Estimating the mean and variance from the median, range, and the size of a sample. BMC Med Res Methodol 5:13. https://doi.org/10.1186/ 1471-2288-5-13

32. Singh JA, Schleck C, Harmsen WS, Lewallen D (2013) Validation Of The Hospital For Special Surgery Knee Questionnaire: Convergent Validity, Responsiveness and Sensitivity To Change. Paper presented at the 2013 ACR/ARHP Annual Meeting, San Diego, CA, October 25-30, 2013

33. Jacobs WC, Christen B, Wymenga AB, Schuster A, van der Schaaf DB, ten Ham A et al (2012) Functional performance of mobile versus fixed bearing total knee prostheses: a randomised controlled trial. Knee Surg Sports Traumatol Arthrosc 20:1450-1455

34. Jolles BM, Grzesiak A, Eudier A, Dejnabadi H, Voracek C, Pichonnaz C et al (2012) A randomised controlled clinical trial and gait analysis of fixed- and mobile-bearing total knee replacements with a five-year follow-up. J Bone Joint Surg Br 94:648-655

35. Kalisvaart MM, Pagnano MW, Trousdale RT, Stuart MJ, Hanssen AD (2012) Randomized clinical trial of rotating-platform and fixed-bearing total knee arthroplasty: no clinically detectable differences at five years. J Bone Joint Surg Am 94:481-489

36. Killen C, Murphy M, Hopkinson W, Harrington MA, Adams WH, Rees HW (2019) Minimum twelve-year follow-up of fixed-vs mobile-bearing total knee arthroplasty: double blinded randomized trial. J Clin Orthop Trauma 11(1):154-159

37. Kim D, Seong SC, Lee MC, Lee S (2012) Comparison of the tibiofemoral rotational alignment after mobile and fixed bearing total knee arthroplasty. Knee Surg Sports Traumatol Arthrosc 20:337-345

38. Kim Y-H, Kim J-S, Choe J-W, Kim H-J (2012) Long-term comparison of fixed-bearing and mobile-bearing total knee replacements in patients younger than fifty-one years of age with osteoarthritis. J Bone Joint Surg Am 94:866-873

39. Kim Y, Park J, Kim J (2019) The long-term results of simultaneous high-flexion mobile-bearing and fixed-bearing total knee arthroplasties performed in the same patients. J Arthroplasty 34(3):501-507

40. Kim YH, Kim DY, Kim JS (2007) Simultaneous mobile- and fixed-bearing total knee replacement in the same patients. a prospective comparison of mid-term outcomes using a similar design of prosthesis. J Bone Joint Surg Br 89:904-910

41. Kim YH, Kim JS (2009) Prevalence of osteolysis after simultaneous bilateral fixed- and mobile-bearing total knee arthroplasties in young patients. J Arthroplasty 24:932-940

42. Kim YH, Kook HK, Kim JS (2001) Comparison of fixed-bearing and mobile-bearing total knee arthroplasties. Clin Orthop Relat Res 392:101-115

43. Kim YH, Park JW, Kim JS (2018) Comparison of high-flexion fixed-bearing and high-flexion mobile-bearing total knee arthroplasties-a prospective randomized study. J Arthroplasty 33:130-135

44. Kim YH, Yoon SH, Kim JS (2009) Early outcome of TKA with a medial pivot fixed-bearing prosthesis is worse than with a PFC mobile-bearing prosthesis. Clin Orthop Relat Res 467:493-503

45. Kim YH, Yoon SH, Kim JS (2007) The long-term results of simultaneous fixed-bearing and mobile-bearing total knee replacements performed in the same patient. J Bone Joint Surg Br 89:1317-1323

46. Ladermann A, Lubbeke A, Stern R, Riand N, Fritschy D (2008) Fixed-bearing versus mobile-bearing total knee arthroplasty: a prospective randomised, clinical and radiological study with midterm results at 7 years. Knee 15:206-210

47. Lampe F, Sufi-Siavach A, Bohlen KE, Hille E, Dries SP (2011) One year after navigated total knee replacement, no clinically relevant difference found between fixed bearing and mobile bearing knee replacement in a double-blind randomized controlled trial. Open Orthop J 5:201-208

48. Lee WC, Kwan YH, Chong HC, Yeo SJ (2017) The minimal clinically important difference for knee society clinical rating system after total knee arthroplasty for primary osteoarthritis. Knee Surg Sports Traumatol Arthrosc 25:3354-3359

49. Lizaur-Utrilla A, Sanz-Reig J, Trigueros-Rentero MA (2012) Greater satisfaction in older patients with a mobile-bearing compared with fixed-bearing total knee arthroplasty. J Arthroplasty 27:207-212

50. Mahoney OM, Kinsey TL, D’Errico TJ, Shen J (2012) The John Insall Award: no functional advantage of a mobile bearing posterior stabilized TKA. Clin Orthop Relat Res 470:33-44

51. Marques CJ, Daniel S, Sufi-Siavach A, Lampe F (2015) No differences in clinical outcomes between fixed- and mobile-bearing computer-assisted total knee arthroplasties and no correlations between navigation data and clinical scores. Knee Surg Sports Traumatol Arthrosc 23:1660-1668

52. Matsuda S, Mizu-uchi H, Fukagawa S, Miura H, Okazaki K, Matsuda $\mathrm{H}$ et al (2010) Mobile-bearing prosthesis did not improve mid-term clinical results of total knee arthroplasty. Knee Surg Sports Traumatol Arthrosc 18:1311-1316

53. Minoda Y, Iwaki H, Ikebuchi M, Yoshida T, Mizokawa S, Itokazu M et al (2015) Mobile-bearing prosthesis and intraoperative gap balancing are not predictors of superior knee flexion: 
a prospective randomized study. Knee Surg Sports Traumatol Arthrosc 23:1986-1992

54. Moher D, Liberati A, Tetzlaff J, Altman DG, Group P (2009) Preferred reporting items for systematic reviews and meta-analyses: the PRISMA statement. J Clin Epidemiol 62:1006-1012

55. Moskal JT, Capps SG (2014) Rotating-platform TKA no different from fixed-bearing TKA regarding survivorship or performance: a meta-analysis. Clin Orthop Relat Res 472:2185-2193

56. Munro JT, Pandit S, Walker CG, Clatworthy M, Pitto RP (2010) Loss of tibial bone density in patients with rotating- or fixedplatform TKA. Clin Orthop Relat Res 468:775-781

57. Namba RS, Inacio MC, Paxton EW, Ake CF, Wang C, Gross $\mathrm{TP}$ et al (2012) Risk of revision for fixed versus mobile-bearing primary total knee replacements. J Bone Joint Surg Am 94:1929-1935

58. Nieuwenhuijse MJ, van der Voort P, Kaptein BL, van der Lindenvan der Zwaag HM, Valstar ER, Nelissen RG (2013) Fixation of high-flexion total knee prostheses: five-year follow-up results of a four-arm randomized controlled clinical and roentgen stereophotogrammetric analysis study. J Bone Joint Surg Am 95:e1411-1411

59. Nutton RW, Wade FA, Coutts FJ, van der Linden ML (2012) Does a mobile-bearing, high-flexion design increase knee flexion after total knee replacement? J Bone Joint Surg Br 94:1051-1057

60. Okamoto N, Nakamura E, Nishioka H, Karasugi T, Okada T, Mizuta $\mathrm{H}$ (2014) In vivo kinematic comparison between mobile-bearing and fixed-bearing total knee arthroplasty during step-up activity. J Arthroplasty 29:2393-2396

61. Pagnano MW, Trousdale RT, Stuart MJ, Hanssen AD, Jacofsky DJ (2004) Rotating platform knees did not improve patellar tracking: a prospective, randomized study of 240 primary total knee arthroplasties. Clin Orthop Relat Res 428:221-227

62. Park C, Kang S, Bae D, Song S (2019) Mid-term clinical and radiological results do not differ between fixed-and mobile-bearing total knee arthroplasty using titanium-nitride-coated posterior-stabilized prostheses: a prospective randomized controlled trial. Knee Surg Sports Traumatol 404 Arthrosc 27(4):1165-1173

63. Pijls BG, Valstar ER, Kaptein BL, Nelissen RG (2012) Differences in long-term fixation between mobile-bearing and fixed-bearing knee prostheses at ten to 12 years' follow-up: a single-blinded randomised controlled radiostereometric trial. J Bone Joint Surg Br 94:1366-1371. https://doi.org/10.1302/0301-620X.94B10.28858

64. Powell AJ, Crua E, Chong BC, Gordon R, McAuslan A, Pitto RP et al (2018) A randomized prospective study comparing mobilebearing against fixed-bearing PFC Sigma cruciate-retaining total knee arthroplasties with ten-year minimum follow-up. Bone Joint $\mathbf{J}$ 100-B:1336-1344

65. Prasad S, Chowdary U, Kamaraj C, Kumar P (2013) Short term outcome comparative study of total knee arthroplasty, rotating platform (mobile bearing) versus fixed bearing (congruent) knee designs. Al Am een J Med Sci 6:253-259

66. Price AJ, Rees JL, Beard D, Juszczak E, Carter S, White S et al (2003) A mobile-bearing total knee prosthesis compared with a fixed-bearing prosthesis. A multicentre single-blind randomised controlled trial. J Bone Joint Surg Br 85(1):62-7

67. Radetzki F, Wienke A, Mendel T, Gutteck N, Delank K-S, Wohlrab D (2013) High flex total knee arthroplasty-a prospective, randomized study with results after 10 years. Acta Orthop Belg 79:536-540

68. Rahman WA, Garbuz DS, Masri BA (2010) Randomized controlled trial of radiographic and patient-assessed outcomes following fixed versus rotating platform total knee arthroplasty. J Arthroplasty 25:1201-1208

69. Saari T, Uvehammer J, Carlsson LV, Herberts P, Regnér L, Kärrholm J (2003) Kinematics of three variations of the Freeman-Samuelson total knee prosthesis. Clin Orthop Relat Res 410:235-247
70. Sappey-Marinier E, de Abreu FGA, O'Loughlin P, Gaillard R, Neyret P, Lustig S et al (2020) No difference in patellar position between mobile-bearing and fixed-bearing total knee arthroplasty for medial osteoarthritis: a prospective randomized study. Knee Surg Sports Traumatol Arthrosc 28:1542-1550

71. Schotanus MGM, Pilot P, Kaptein BL, Draijer WF, Tilman PBJ, Vos $R$ et al (2017) No difference in terms of radiostereometric analysis between fixed- and mobile-bearing total knee arthroplasty: a randomized, single-blind, controlled trial. Knee Surg Sports Traumatol Arthrosc 25:2978-2985

72. Scuderi GR, Hedden DR, Maltry JA, Traina SM, Sheinkop MB, Hartzband MA (2012) Early clinical results of a high-flexion, posterior-stabilized, mobile-bearing total knee arthroplasty: a US investigational device exemption trial. J Arthroplasty 27:421-429

73. Shemshaki H, Dehghani M, Eshaghi MA, Esfahani MF (2012) Fixed versus mobile weight-bearing prosthesis in total knee arthroplasty. Knee Surg Sports Traumatol Arthrosc 20:2519-2527. https://doi. org/10.1007/s00167-012-1946-1

74. Sterne JAC, Savović J, Page MJ, Elbers RG, Blencowe NS, Boutron I, et al (2019) RoB 2: a revised tool for assessing risk of bias in randomised trials. BMJ 366:14898. https://doi.org/10.1136/bmj.14898

75. Stukenborg-Colsman C, Ostermeier S, Hurschler C, Wirth CJ (2002) Tibiofemoral contact stress after total knee arthroplasty: comparison of fixed and mobile-bearing inlay designs. Acta Orthop Scand 73:638-646

76. Tibesku CO, Daniilidis K, Skwara A, Dierkes T, Rosenbaum D, Fuchs-Winkelmann S (2011) Gait analysis and electromyography in fixed- and mobile-bearing total knee replacement: a prospective, comparative study. Knee Surg Sports Traumatol Arthrosc 19:2052-2059

77. Tienboon P, Jaruwangsanti N, Laohasinnurak P (2012) A prospective study comparing mobile-bearing versus fixed-bearing type in total knee arthroplasty using the free-hand-cutting technique. J Med Assoc Thai 95(Suppl 10):S77-86

78. Tiwari V, Meshram P, Park CK, Bansal V, Kim TK (2019) New mobile-bearing TKA with unique ball and socket post-cam mechanism offers similar function and stability with better prosthesis fit and gap balancing compared to an established fixed-bearing prosthesis. Knee Surg Sports Traumatol Arthrosc 27:2145-2154

79. Tjornild M, Soballe K, Hansen PM, Holm C, Stilling M (2015) Mobile- vs. fixed-bearing total knee replacement. Acta Orthop $86: 208-214$

80. van de Groes S, van der Ven P, Kremers-van de Hei K, Koeter S, Verdonschot N (2015) Flexion and anterior knee pain after high flexion posterior stabilized or cruciate retaining knee replacement. Acta Orthop Belg 81:730-737

81. van der Voort P, Pijls BG, Nouta KA, Valstar ER, Jacobs WC, Nelissen RG (2013) A systematic review and meta-regression of mobilebearing versus fixed-bearing total knee replacement in 41 studies. Bone Joint J 95-B:1209-1216

82. Van Hamersveld KT, Marang-Van De Mheen PJ, Van Der Heide HJL, Der Linden-Van V, Der Zwaag HMJ, Valstar ER, Nelissen R (2018) Migration and clinical outcome of mobile-bearing versus fixed-bearing single-radius total knee arthroplasty. Acta Orthop 89:190-196

83. Vasdev A, Kumar S, Chadha G, Mandal SP (2009) Fixed- versus mobile-bearing total knee arthroplasty in Indian patients. J Orthop Surg (Hong Kong) 17:179-182

84. Wang K, Zhang FF, Yan X, Shen Y, Cai W, Xu J et al (2020) Superior mid- to long-term clinical outcomes of mobile-bearing total knee arthroplasty compared to fixed-bearing: a meta-analysis based on a minimum of 5 years of study. J Knee Surg. https://doi.org/10. 1055/s-0040-1709490

85. Wen Y, Liu D, Huang Y, Li B (2011) A meta-analysis of the fixedbearing and mobile-bearing prostheses in total knee arthroplasty. Arch Orthop Trauma Surg 131:1341-1350 
86. Wohlrab D, Hube R, Zeh A, Hein W (2009) Clinical and radiological results of high flex total knee arthroplasty: a 5 year follow-up. Arch Orthop Trauma Surg 129:21-24

87. Wolterbeek N, Garling EH, Mertens BJ, Nelissen RG, Valstar ER (2012) Kinematics and early migration in single-radius mobile- and fixed-bearing total knee prostheses. Clin Biomech (Bristol, Avon) 27:398-402

88. Woolson ST, Epstein NJ, Huddleston JI (2011) Long-term comparison of mobile-bearing vs fixed-bearing total knee arthroplasty. J Arthroplasty 26:1219-1223

89. Wylde V, Learmonth I, Potter A, Bettinson K, Lingard E (2008) Patient-reported outcomes after fixed- versus mobile-bearing total knee replacement: a multi-centre randomised controlled trial using the Kinemax total knee replacement. J Bone Joint Surg Br 90:1172-1179

Publisher's Note Springer Nature remains neutral with regard to jurisdictional claims in published maps and institutional affiliations. 